\title{
Durval Marcondes
}

Fundador do movimento psicanalítico brasileiro, Durval Bellegarde Marcondes, nasceu em São Paulo, no dia 27 de novembro de 1899. Em 1924, formou-se psiquiatra pela Faculdade de Medicina de São Paulo. No ano seguinte introduz as idéias da Psicanálise de Sigmund Freud na atividade clínica brasileira. Em 1927, escreve a Freud, comunicando a fundação, junto com Franco da Rocha, da Sociedade Brasileira de Psicanálise, a primeira da América Latina, que renasce como Grupo Psicanalítico de São Paulo em junho de 1944 e, em 1951, no Congresso da International Psychoanalytical Association - IPA, em Amsterdã, torna-se a Sociedade Brasileira de Psicanálise de São Paulo - SBPSP, presidida por Durval nas gestões 1944/1949, 1955/1956 e 1967/1969.

O lançamento da Revista Brasileira de Psychanalyse, em 1928, marcou o início das atividades da sociedade. Freud chegou a receber um exemplar da publicação e a responder por carta, incentivando sua continuidade. Em 1951, constituiuse oficialmente a Sociedade Brasileira de Psicanálise de São Paulo e, em 1967, a Revista foi relançada por Marcondes, Virgínia Bicudo, Luiz Almeida Prado Galvão, Laertes Ferrão e Armando Ferrari. Desde então vem sendo publicada trimestralmente.

Em 1927, Durval Marcondes funda o serviço de higiene mental nas instituições escolares. Nos anos seguintes, empenha-se na formação da Universidade de São Paulo como universidade modelo, onde cria as primeiras cátedras brasileiras de Psicologia, de Psicanálise e de Higiene Mental. Organizou um grupo de "educadoras sanitárias", que trabalhavam com atendimento clínico infantil e, de forma inovadora, em moldes interdisciplinares.

Em 1954, organizou o primeiro curso de especialização em Psicologia Clínica, na Faculdade de Filosofia da Universidade de São Paulo. Foi assistente de Psicologia Social (1934-38) e professor de Psicanálise e de Higiene (1934-37) no então Instituto de Higiene, hoje Faculdade de Higiene e Saúde Pública da Universidade de São Paulo - USP.

Durval Bellegarde Marcondes faleceu em 27 de setembro de 1981. 